\title{
Transforming growth factor $\beta 1$ protein and mRNA levels in inflammatory bowel diseases: towards solving the contradictions by longitudinal assessment of the protein and mRNA amounts
}

\author{
Anna Liberek1, Zbigniew Kmieć2, Piotr M. Wierzbicki², Joanna Jakóbkiewicz-Banecka³, \\ Tomasz Liberek ${ }^{4}$ Grażyna Łuczak5 ${ }^{5}$ Katarzyna Plata-Nazar5, Magdalena Słomińska-Frączek5 \\ Lucyna Kaszubowska², Magdalena Gabig-Cimińska6 and Alicja Węgrzyn ${ }^{7 凶}$
}

1Faculty of Health Sciences with Subfaculty of Nursing, Medical University of Gdańsk, Gdańsk, Poland; ${ }^{2}$ Department of Histology, Medical University of Gdańsk, Gdańsk, Poland; 32Department of Molecular Biology, University of Gdańsk, Gdańsk, Poland; ${ }^{4}$ Department of Nephrology, Transplantology and Internal Medicine, Medical University of Gdańsk, Gdańsk, Poland; 5 Department of Pediatrics, Pediatric Gastroenterology, Hepatology and Nutrition, Medical University of Gdańsk, Gdańsk, Poland; 'Laboratory of Molecular Biology (affiliated with University of Gdańsk), Institute of Biochemistry and Biophysics, Polish Academy of Sciences, Gdańsk, Poland; 7Department of Microbiology, University of Szczecin,

Szczecin, Poland

Previously published studies on levels of the transforming growth factor- $\beta 1$ (TGF- $\beta 1$ ) protein and mRNA of the corresponding gene in patients suffering from inflammatory bowel diseases (IBD) gave varying results, leading to contradictory conclusions. To solve the contradictions, we aimed to assess longitudinally TGF- $\beta 1$ protein and mRNA levels at different stages of the disease in children suffering from IBD. The study group consisted of 19 pediatric patients with IBD at the age between 3.5 and 18.4 years. The control group consisted of 42 children aged between 2.0 and 18.0 years. The plasma TGF- $\beta 1$ concentration was measured with ELISA. mRNA levels of the TGF- $\beta 1$ gene isolated from samples of the intestinal tissue were assessed by reverse transcription and real-time PCR. Levels of TGF- $\beta 1$ protein in plasma and corresponding mRNA in intestinal tissue were significantly higher in IBD patients than in controls. TGF- $\beta 1$ and corresponding transcripts were also more abundant in plasma and intestinal tissue, respectively, in patients at the active stage of the disease than during remission. In every single IBD patient, plasma TGF- $\beta 1$ level and mRNA level in intestinal tissue was higher at the active stage of the disease than during remission. Levels of TGF- $\beta 1$ and corresponding mRNA are elevated during the active stage of IBD but not during the remission. Longitudinal assessment of this cytokine in a single patient may help to monitor the clinical course of IBD.

Key words: Crohn's disease; ulcerative colitis; Transforming Growth Factor- $\beta 1$; longitudinal assessment of TGF- $\beta 1$ level

Received: 28 October, 2013; revised: 02 December, 2013; accepted: 07 December, 2013; available on-line: 30 December, 2013

\section{INTRODUCTION}

Transforming growth factor- $\beta 1$ (the isoform 1 of transforming growth factor type beta, abbreviated as TGF- $\beta 1$ ) is a cytokine with immunomodulatory activity ( $\mathrm{Li}$ et al., 2006; Rahimi \& Leof, 2007). It is known to affect cell proliferation and development (Heldin et al., 2009). This cytokine has an immunosuppressive function, and thus it was described as a factor involved in preventing autoimmune and chronic inflammatory reactions (Bommireddy et al., 2006; Saxena et al., 2008). Because of its effects on immunological response, it is not a surprise that levels of both the TGF- $\beta 1$ protein and mRNA of the corresponding gene were determined in patients suffering from inflammatory bowel disease (IBD), a chronic inflammation which occurs in two main clinical forms: Crohn's disease (CD) and ulcerative colitis (UC). However, different studies gave varying results, leading to contradictory conclusions on the involvement of TGF- $\beta 1$ in IBD.

In the early report on expression of the TGF- $\beta$ gene, an increased level of corresponding mRNA was detected by in situ hybridization in affected mucosa from patients with both $\mathrm{CD}$ and $\mathrm{UC}$ with active disease (Babyatsky et al., 1996). In tissue samples from these patients, TGF- $\beta 1$ mRNA localized mostly to cells of the lamina propria with the highest expression in inflammatory cells closest to the luminal surface. It was, therefore, concluded that TGF- $\beta$ may be a key cytokine during periods of active inflammation, modulating epithelial cell restitution and functional features of cells within the lamina propria (Babyatsky et al., 1996). Similar results were reported three years later, when increased levels of TGF- $\beta 1$ mRNA, relative to controls, in tissue samples from CD patients were measured, and localization of this cytokine (assessed by immunohistochemistry) was predominant in lamina propria cells and in the lymphocytes closest to the luminal surface (di Mola et al., 1999). Nevertheless, enhanced expression of the TGF- $\beta 1$ gene was also evident in epithelial cells, and fibroblasts of CD tissue samples (di Mola et al., 1999). Contrary to those reports, another research group reported an unchanged expression (relative to the control group) of TGF- $\beta 1$ in the colonic epithelium of adolescent IBD patients (as assessed by in situ hybridization), despite an increased number of TGF- $\beta 1$-positive cells in the lamina propria, during the active stage of the disease (Xian et al., 1999).

Even more doubts about the expression of the TGF- $\beta 1$ in IBD patients appeared when plasma levels of this cytokine were determined. Although baseline TGF- $\beta 1$ levels were higher in UC patients than in controls, after 7 days of a conventional treatment concentration of this cytokine increased in patients who responded to the therapy, but not in those who did not

e-mail: alawegrzyn@yahoo.com

Abbreviations: TGF- $\beta 1$, Transforming growth factor- $\beta 1$. 
respond (Sambuelli et al., 2000). These results suggested a negative correlation between TGF- 11 plasma levels and the activity of the disease. On the other hand, a parallel study demonstrated that TGF- $\beta 1$ plasma concentrations were not significantly different in IBD (CD and UC) patients and healthy controls (Sturm et al., 2000). Moreover, stratification of IBD patients according to the disease activity also did not reveal any substantial differences (Sturm et al., 2000). Another group found a higher level of TGF- $\beta 1$ in plasma of pediatric IBD patients (both $\mathrm{CD}$ and $\mathrm{UC}$ ) during remission than at the active stage of the disease (Kader et al., 2005). In contrast, other authors reported no significant differences in the plasma level of TGF- $\beta 1$ between IBD patients and controls, while considerably higher TGF- $\beta 1$ level occurred in UC patients during active disease than at the remission stage (Kilic et al., 2009). Furthermore, an increased plasma TGF- $\beta 1$ level was also reported in pediatric UC patients in comparison to controls (Wedrychowicz et al., 2011).

Recent works reported an enhanced expression of the TGF- $\beta 1$ gene in intestinal tissue of CD (Burke et al., 2008) and UC (Stadnicki et al., 2009) patients relative to controls. Interestingly, it has been suggested that high levels of TGF- $\beta 1$ in healthy bowels of patients who undergo ileo-colonic resection for CD are associated with early clinical disease recurrence (Scarpa et al., 2009). Finally, when pediatric IBD (both $\mathrm{CD}$ and $\mathrm{UC}$ ) patients were investigated, TGF- $\beta 1 \mathrm{mRNA}$ levels were significantly higher in intestinal tissue samples collected during the relapse of the disease than in those taken during the remission or in the control group, while no statistically significant differences in plasma TGF- $\beta 1$ levels were found between any of these groups (though a tendency for higher levels in IBD patients was observed with borderline $\mathrm{p}$ value of 0.06) (Liberek et al., 2013). In addition, higher levels of mRNA of the TGF- $\beta 1$ gene were evident in affected areas of intestinal tissue derived from IBD pediatric patients than in unaffected areas of the same patients (Liberek et al., 2013).

The short review of studies on levels of expression of the gene coding for TGF- $\beta 1$ in IBD patients, presented above, indicates that there are discrepancies between results reported by various groups, which led to contradictory conclusions on TGF- $\beta 1$ levels during the disease, relative to controls. We assumed that one of the problems that might cause obtaining such different results in various studies might arise from the fact that levels of either TGF- $\beta 1$ protein or corresponding mRNA were compared between samples obtained from different groups of patients, i.e. in cross-sectional studies. To solve these contradictions, we used a longitudinal approach by comparing results obtained from biological samples of the same patients taken at different stages of the disease. Besides calculating statistical values, we have also analyzed tendency of differences in the measured values in samples from each particular patient in the active stage of the disease and during remission.

\section{MATERIALS AND METHODS}

Patients. The study group consisted of 19 patients with IBD (10 boys and 9 girls), among which 7 were diagnosed for CD and 12 for UC at the age between 3.5 and 18.4

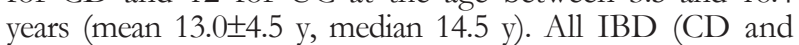
UC) patients were treated with the usual anti-inflammatory drug (5-aminosalicylic acid, 5ASA) at the standard recommended doses. A group of 42 children represented the control group, which consisted of 20 girls and 22 boys at the age between 2.0 and 18.0 years (mean $11.0 \pm 5.0 \mathrm{y}$, median $11.0 \mathrm{y}$ ), who underwent endoscopy because of episodes of gastrointestinal (GI) bleedings; in this group of patients, inflammatory processes, immune disorders, malignancies and nutritional abnormalities were excluded. None of the children from the control group received immunomodulating drugs at least 6 months prior to the study.

Clinical procedures. Among IBD patients, severity of $\mathrm{CD}$ and UC were estimated according to the Hyams scale (Pediatric Crohn's Disease Activity Index, PCDAI) and the Truelove-Witts scale, respectively (Truelove \& Witts, 1954; Hyams et al., 1991). In all IBD patients, both blood and bowel tissue samples were obtained (during endoscopy in the latter cases, where all samples were colonic) in the acute phase of the disease and in remission. Endoscopic and histological classifications of intestinal mucosa were performed according to the Porto criteria (IBD Working Group of the European Society for Paediatric Gastroenterology, Hepatology and Nutrition, 2005). In children from the control group, the samples were withdrawn once, when performing obligatory diagnostic procedures.

Estimation of TGF- $\beta 1$ level in plasma. The plasma TGF- $\beta 1$ level was estimated by ELISA as described previously (Liberek et al., 2013), and according to the manufacturer's instruction (Quantikine TGF- $\beta 1$ R\&D Systems, USA).

Estimation of mRNA level of the gene coding for TGF- 31 . mRNA levels of the TGF- $\beta 1$ gene in samples of the intestinal tissue were estimated by reverse transcription and real-time PCR as described previously (Liberek et al., 2013). Briefly, total RNA was isolated by employing the Total RNA Prep Plus kit (A\&A Biotechnology, Poland). Each reverse transcription reaction was performed in total volume of $10 \mu \mathrm{l}$, with $1 \mu \mathrm{g}$ of RNA, $0.25 \mu \mathrm{g}$ of oligo T18, and M-MLVenzyme (Promega, Madison, WI, USA). For real-time PCR reactions, primers specific to TGF- $\beta 1$ (primers annotated TGF- $\beta 1$ and TGF $\beta-2$ ) and the control gene $A C T B$ (primers annotated bact1-1 and bact1-2), described previously (Liberek et al., 2013), were used (the sequences of these primers were as follows: TGF- $\beta 1$ : 5'CAG CAA CAA T'TC CTG GCG ATA CC; TGFß-2, 5'-CGA AAG CCC TCA ATT TCC CCT C; bact1-1, 5'TGT GCC CAT CTA CGA GGG GTA TGC; bact1-2, 5'-GGT ACATGG TGG TGC CGC CAG ACA). Each real-time PCR reaction was performed in total volume of $20 \mu \mathrm{l}$, with $0.4 \mu \mathrm{l} \mathrm{cDNA}, 180 \mathrm{nM}$ each of two specific primers and iQSybrGreen Supermix kit (Bio-Rad), employing iCycler iQ (Bio-Rad). The reactions were run in triplicates and the data obtained were averaged. Data analysis and calculations were done with iQ ver. 3.1 software (Bio-Rad). The results for the $A C T B$ gene were used as controls to normalize the values in the $\Delta \Delta \mathrm{Ct}$ quantification method.

Statistical analysis. Statistical analysis of the results was performed using non-parametric tests: the MannWhitney test for comparison of two groups, the ANOVA Kruskal-Wallis test for comparison of several groups. For comparison of values obtained from the same patient at different stages of the disease, the Wilcoxon signed rank test for paired values was used. The results were considered statistically significant when $p<0.05$. The calculations were performed employing Statistica 7 software (StatSoft Inc. Tulsa, OK, USA).

Ethical considerations. This study was approved by the Independent Bio-Ethical Committee for Research at the Medical University of Gdańsk (NKEBN/13/2004). Informed consent was obtained from parent(s) of each patient included in the study. 


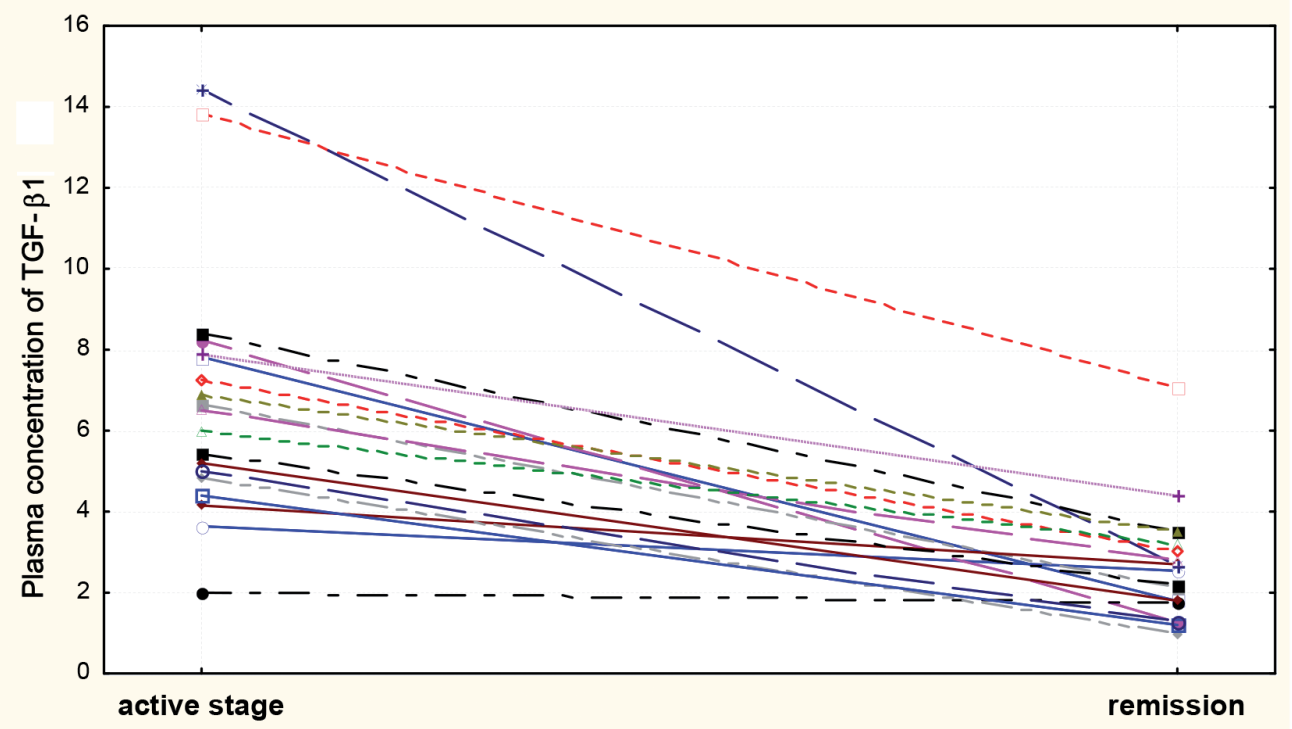

Figure 1. Comparison of plasma TGF- $\beta 1$ concentrations $(\mathrm{ng} / \mathrm{ml})$ in the group of IBD patients at the active stage of the disease and during the remission.

Each line represents changes in TGF- $\beta 1$ levels observed in a single patient separately. The results obtained for each particular patient are represented by the same kind and color of symbols and lines in this figure and in Fig. 2. Statistical analysis indicated a significantly higher plasma TGF- $\beta 1$ level at the active stage of the disease than during remission $(p<0.001)$.

\section{RESULTS}

Since previously published studies reported contradictory results of estimation of levels of the TGF- $\beta 1$ protein and mRNA of the corresponding gene in plasma and intestine tissue of patients suffering from IBD (reviewed in Introduction). In order to solve these contradictions, we have measured these parameters in pediatric patients with IBD (the groups with CD and UC were included, but no statistically significant differences between these two groups were detected in all measured parameters, with $p>0.05$ in each analysis, therefore, CD and UC patients will be described together as IBD patients in further text). However, contrary to previous studies, we have not only considered mean values or medians from the studied groups relative to those of controls, but we also compared protein and mRNA levels in samples from every single patient taken at the active disease and during remission. Therefore, despite the fact that such a study required double endoscopy for every patient, we were able to compare not only statistical parameters of particular groups, but also to observe changes in the measured biochemical parameters occurring in every single patient at different stages of the disease.

When estimating levels of the TGF- $\beta 1$ protein in plasma (Table 1), we found that the median concentration of this protein was significantly higher in IBD patients than in controls $(6.03 \mathrm{ng} / \mathrm{ml}$ (range: $2.0-14.44)$ vs. 2.79 $\mathrm{ng} / \mathrm{ml}$ (range: $0.54-55.1$ ) $p=0.005$ ). TGF- $\beta 1$ was also more abundant in plasma of patients being at the active stage of the disease than in plasma of the same group of patients during remission $(6.03 \mathrm{ng} / \mathrm{ml}$ (range: 2.0 14.44) vs. $1.94 \mathrm{ng} / \mathrm{ml}$ (range: 0.96-7.09) $p=0.03$ ). However, no statistically significant differences were observed between patients at the remission stage and the control group ( $p=0.26)$. Importantly, in every single IBD patient, plasma TGF- $\beta 1$ level was higher at the active stage of the disease than during remission $(p<0.001)$. These differences were pronounced to various extent in different patients, nevertheless, no exception from the rule was noted (Fig. 1).

Because of these intriguing results, we have analyzed levels of mRNA of the gene coding for TGF- $\beta 1$ in samples of intestinal tissue withdrawn from controls (single endoscopy) and from IBD patients during both stages of the disease (two endoscopic events for each patient, one at the active disease stage and another one during remission) (Table 2). We have calculated that the median TGF- $\beta 1$ mRNA level (expressed in arbitrary units) was higher in patients at the active disease stage than in controls $(0.08453$ (range: $0.00291-0.31250)$ vs. 0.04028 (range: 0.00103-0.82469)

Table 1. Plasma TGF- $\beta 1$ concentration in the control group, and in the group of IBD patients, measured at the active stage of the disease and during the remission.

\begin{tabular}{lllllll}
\hline \multirow{2}{*}{ Group } & \multirow{2}{*}{$\mathrm{N}$} & \multicolumn{2}{l}{ Plasma TGF- $\beta$ 1 concentration $(\mathrm{ng} / \mathrm{ml})^{\mathrm{b}}$} & & Max. & SD \\
\cline { 2 - 7 } & & Mean & Median & Min. & 55.10 & 11.60 \\
\hline Controla & 42 & 6.96 & 2.79 & 0.54 & & \\
\hline IBD patients & 19 & & & & 14.44 & 4.16 \\
\hline Active disease & & 7.10 & 6.03 & 2.00 & 7.09 & 1.73 \\
\hline Remission & 2.41 & 1.94 & 0.96 & \\
\hline
\end{tabular}

aThis group of patients was reported previously (Liberek et al., 2013). bStatistical analysis: the median in IBD patients at the active stage vs. controls, $p=0.005$; the median in IBD patients during remission vs. controls, $\mathrm{p}=0.26$; the median in IBD patients at the active stage vs. the same group of patients during remission, $p=0.03$. 


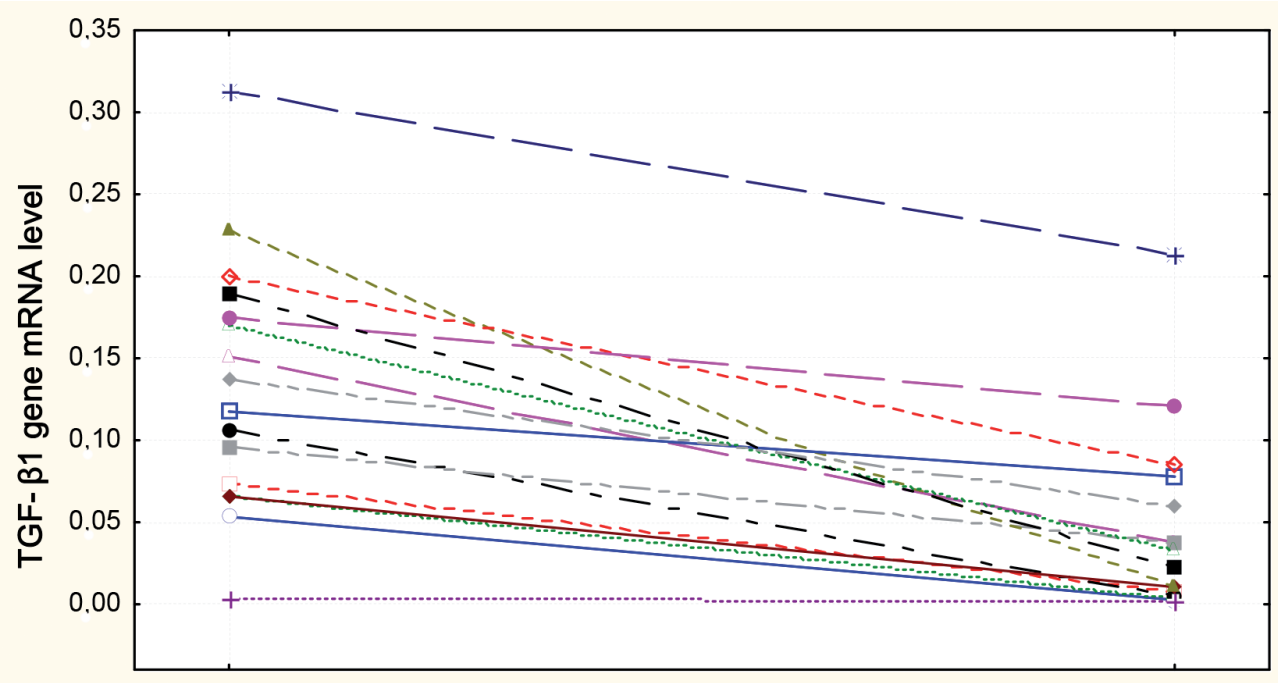

active disaese

remission

Figure 2. Comparison of mRNA levels of the TGF- $\beta 1$ gene (arbitrary units) in intestinal tissue samples taken from IBD patients at the active stage of the disease and during the remission.

Each line represents changes in levels of mRNA of the TGF- $\beta 1$ gene observed in a single patient separately. The results obtained for each particular patient are represented by the same kind and color of symbols and lines in this figure and in Fig. 1. Statistical analysis indicated a significantly higher TGF- $\beta 1$ mRNA level at the active stage of the disease than during remission $(p<0.001)$.

$p=0.002)$, however, the difference in this parameter between patients during remission and the control group did not reach statistical significance $(p=0.05)$. When we compared two stages of the disease in the same group of patients, we found that the median level of TGF- $\beta 1$ mRNA was higher during the active disease than during remission (0.08453 (range: $0.00291-0.31250)$ vs. 0.00906 (range: 0.00191-0.21250) $p<0.001)$. More importantly, we found that in every single patient, TGF- $\beta 1$ mRNA level measured at the active disease stage was higher than during remission $(p<0.001)$. No exception from this rule was found (Fig. 2).

\section{DISCUSSION}

TGF- $\beta 1$, a cytokine with generally immunosuppressive activity, undoubtedly plays a role in gut inflammation, including IBD (MacDonald et al., 2001). Nevertheless, during the last two decades, several articles were published in which various authors measured levels of TGF- $\beta 1$ or mRNA of the corresponding gene under various conditions, and reported increased levels in IBD patients $v s$. controls, decreased levels in IBD patients vs. controls or no significant differences (see Introduction for details). These contradictory results are intriguing, especially in the light of discussions on molecular mechanisms by which TGF- $\beta 1$ might influence IBD (MacDonald et al., 2001).

Because of the above problem, we have performed studies towards solving the contradictions reported in previous publications. Our intention was to compare not only mean values or other statistical parameters, like median, obtained after analyses of samples from different groups under study, but also to compare changes in the protein or mRNA levels in every IBD patient at two stages of the disease: the active stage and the remission. Our results indicated that (apart from significantly increased levels of TGF- $\beta 1$ and corresponding mRNA in plasma and intestinal tissue, respectively, in IBD patients relative to the control group) in each IBD patient, plasma TGF- $\beta 1$ level was higher at the active stage of the disease than during remission, and in each IBD patient, TGF- $\beta 1 \mathrm{mRNA}$ level in intestinal tissue was higher at the active stage of the disease than during remission. Importantly, in both analyses, no single exception from the rule was found, i.e. the measured TGF- $\beta 1$ protein and corresponding mRNA levels were higher during the active disease than during remission in every single patient. In Figs. 1 and 2, showing levels of TGF- $\beta 1$ protein

Table 2. Levels of mRNA of the TGF- $\beta 1$ gene in intestinal tissue samples taken from members of the control group, and from the group of IBD patients undergoing endoscopy twice: at the active stage of the disease and during the remission.

\begin{tabular}{|c|c|c|c|c|c|c|}
\hline \multirow{2}{*}{ Group } & \multirow{2}{*}{$\mathrm{N}$} & \multicolumn{5}{|c|}{ Levels of mRNA of the TGF- $\beta 1$ gene (arbitrary units) ${ }^{b}$} \\
\hline & & Mean & Median & Min. & Max. & SD \\
\hline Controla & 42 & 0.08591 & 0.04028 & 0.00103 & 0.82469 & 0.16012 \\
\hline IBD patients & 19 & & & & & \\
\hline Active disease & & 0.11557 & 0.08453 & 0.00291 & 0.31250 & 0.09229 \\
\hline Remission & & 0.03305 & 0.00906 & 0.00191 & 0.21250 & 0.06448 \\
\hline
\end{tabular}

aThis group of patients was reported previously (Liberek et al., 2013). bStatistical analysis: the median in IBD patients at the active stage vs. controls, $p=0.002$; the median in IBD patients during remission vs. controls, $p=0.05$; the median in IBD patients at the active stage vs. the same group of patients during remission, $p<0.001$. 
and $\mathrm{mRNA}$, respectively, the results obtained for each particular patient are represented by the same kind and color of symbols and lines. It appears that in some patients a very high level of the TGF- $\beta 1$ protein in plasma correlated with a high mRNA level of the corresponding gene in intestinal tissue, however, the fold differences between active disease and remission was not necessary the same for protein and mRNA levels in individual patients. This is not a surprise, as different kinds of biological material (plasma vs. intestinal tissue) were used for measurement of protein and mRNA amounts. Nevertheless, the direction and tendency of changes in these parameters were the same in each patient. Therefore, we conclude that expression of the gene coding for TGF- $\beta 1$ is enhanced during the active stage of $\mathrm{IBD}$, relative to remission of the disease, at least in pediatric patients.

The question remains as to the reasons for reported contradictions in levels of TGF- $\beta 1$ in IBD patients. One might suggest a possible influence of genetic background of different groups of patients investigated by different authors, particularly polymorphisms of the TGF- $\beta 1$ gene. However, recent studies indicated a lack of correlation between common polymorphisms in this gene and clinical parameters of IBD (Liberek et al., 2011). Therefore, it is more likely that the problems with contradictory results could arise from technical difficulties of studies. One obvious difficulty is based on collecting an appropriate control group. Usually a control group consists of patients suffering from other diseases rather than from healthy volunteers. Such a situation takes place especially often when invasive procedures are employed, which may be exemplified by endoscopy used in this and similar studies. Although for many investigations such composition of a control group might not result in any problems, in studies focused on TGF- $\beta 1$ this may cause potential difficulty because this cytokine is involved in various immunological reactions, and thus, its level may be altered in a number of diseases unrelated to IBD. If this is the case, and if a patient, or several patients, with a transiently increased or decreased expression of TGF- $\beta 1$ is/are included in the control group, the mean and/or median control value(s) could be significantly influenced, giving false reference value in comparison to the studied group of patients.

The reality of the problem described above may be demonstrated even in this study. When analyzing the values of plasma TGF- $\beta 1$ level (Table 1), it is intriguing that although in vast majority of samples withdrawn from members of the control group the level was generally low, the maximal detected value was dramatically higher than that in any IBD patient. Such values may affect the statistical analyses considerably when mean values are calculated. Note that such a high maximal value of the plasma TGF- $\beta 1$ level was detected in the control group despite the fact that in this group of patients, inflammatory processes, immune disorders, malignancies and nutritional abnormalities were excluded, and none of the patients received immuno-modulating drugs at least 6 months prior to the study (as described in Materials and Methods). Moreover, a similar phenomenon was observed when the mRNA level was estimated (Table 2); in this test, the maximal level detected in the control group was over 10 times higher than the mean value and over 20 times higher than the median. Therefore, we suggest that in such cases, comparison of partic- ular parameters in each patient at different stages of the disease may be especially informative, and can be considered together with analyses based on calculation and comparison of mean or median values from different groups. If a longitudinal assessment of particular parameters is possible for many individual patients, and if a general tendency is observed in most or even all patients, the conclusions might be considered as especially well supported by experimental results.

Finally, since the results of TGF- $\beta 1$ protein and mRNA levels presented in Figs. 1 and 2 are so unequivocal, we suggest that longitudinal assessment of this cytokine in a single patient may help to monitor the clinical course of IBD.

\section{Conflict of Interest}

No potential conflict of interest relevant to this article was reported.

\section{Acknowledgements}

Ministry of Science and Higher Education, Poland (project grant no. 2P05E 125 27).

\section{REFERENCES}

Babyatsky MW, Rossiter G, Podolsky DK (1996) Expression of transforming growth factors alpha and beta in colonic mucosa in inflammatory bowel disease. Gastroenterology 110: 975-984.

Bommireddy R, Pathak LJ, Martin J et al. (2006) Self-antigen recognition by TGF $\beta 1$-deficient T cells causes their activation and systemic inflammation. Lab Invest 86: 1008-1019.

Burke JP, Ferrante M, Dejaegher K et al. (2008) Transcriptomic analysis of intestinal fibrosis-associated gene expression in response to medical therapy in Crohn's disease. Inflamm Bowel Dis 14: 1197-1204.

di Mola FF, Friess H, Scheuren A et al. (1999) Transforming growth factor-betas and their signaling receptors are coexpressed in Crohn's disease. Ann Surg 229: 67-75.

Heldin CH, Landström M, Moustakas A (2009) Mechanism of TGF-beta signaling to growth arrest, apoptosis, and epithelialmesenchymal transition. Curr Opin Cell Biol 21: 166-176.

Hyams JS, Ferry GD, Mandel FS et al. (1991) Development and validation of a pediatric Crohn's disease activity index. J Pediatr Gastroenterol Nutr 12: 439-447.

IBD Working Group of the European Society for Paediatric Gastroenterology, Hepatology and Nutrition (2005) Inflammatory bowel disease in children and adolescents: recommendations for diagnosis - the Porto criteria. J Pediatr Gastroenterol Nutr 41: 1-7.

Kader HA, Tchernev VT, Satyaraj E et al. (2005) Protein microarray analysis of disease activity in pediatric inflammatory bowel disease demonstrates elevated serum PLGF, IL-7, TGF- $\beta 1$, and IL-12p40 levels in Crohn's disease and ulcerative colitis patients in remission versus active disease. Am I Gastroenterol 100: 414-423.

Kilic ZMY, Ayaz S, Ozin Y et al. (2009) Plasma transforming growth factor- $\beta 1$ level in inflammatory bowel disease Turk J Gastroenterol 20: 165-170.

Li MO, Wan YY, Sanjabi S, et al. (2006) Transforming growth factor-beta regulation of immune responses. Annu Rev Immunol 24: 99-146.

Liberek A, Jakóbkiewicz-Banecka J, Kloska A et al. (2011) Clinical parameters of inflammatory bowel disease in children do not correlate with four common polymorphisms of the transforming growth factor $\beta 1$ gene. Acta Biochim Pol 58: 641-644.

Liberek A, Kmieć Z, Kartanowicz D et al. (2013) The mRNA level of the transforming growth factor $\beta 1$ gene, but not the amount of the gene product, can be considered as a potential prognostic parameter in inflammatory bowel diseases in children. Int $J$ Colorectal Dis 28: 165-172.

MacDonald TT, Bell I, Monteleone G (2011) The opposing roles of IL-21 and TGF $\beta 1$ in chronic inflammatory bowel disease. Biochem Soc Trans 39: 1061-1066.

Rahimi RA, Leof EB (2007) TGF-beta signaling: a tale of two responses. I Cell Biochem 102: 593-608.

Sambuelli A, Diez RA, Sugai E et al. (2000). Serum transforming growth factor-beta1 levels increase in response to successful anti-inflammatory therapy in ulcerative colitis. Aliment Pharmacol Ther 14: 1443-1449. 
Saxena V, Lienesch DW, Zhou M et al. (2008) Dual roles of immunoregulatory cytokine TGF-beta in the pathogenesis of autoimmunity-mediated organ damage. J Immunol 180: 1903-1912.

Scarpa M, Bortolami M, Morgan SL et al. (2009) TGF-31 and IGF-1 production and recurrence of Crohn's disease after ileo-colonic resection. J Surg Res 152: 26-34.

Stadnicki A, Machnik G, Klimacka-Nawrot E et al. (2009) Transforming growth factor-betal and its receptors in patients with ulcerative colitis. Int Immunopharmacol 9: 761-766.

Sturm A, Schulte C, Schatton R et al. (2000) Transforming growth factor-beta and hepatocyte growth factor plasma levels in patients with inflammatory bowel disease. Eur J Gastroenterol Hepatol 12: 445-450.
Truelove SC, Witts LJ (1954) Cortisone in ulcerative colitis; preliminary report on a therapeutic trial. $\mathrm{Br}$ Med J 2: 375-378.

Wedrychowicz A, Kowalska-Duplaga K, Jedynak-Wasowicz U et al. (2011) Serum concentrations of VEGF and TGF- $\beta 1$ during exclusive enteral nutrition in IBD. I Pediatr Gastroenterol Nutr 53: 150-155.

Xian CJ, Xu X, Mardell CE et al. (1999) Site-specific changes in transforming growth factor-alpha and -betal expression in colonic mucosa of adolescents with inflammatory bowel disease. Scand J Gastroenterol 34: 591-600. 